\title{
College complaints against resident physicians in Canada: a retrospective analysis of Canadian Medical Protective Association data from 2013 to 2017
}

\author{
Charlotte Crosbie MD JD, Allan McDougall MA PhD, Harpreet Pangli MD, \\ Riyad B. Abu-Laban MD MHSc, Lisa A. Calder MD MSc
}

\section{Abstract}

Background: An understanding of regulatory complaints against resident physicians is important for practice improvement. We describe regulatory college complaints against resident physicians using data from the Canadian Medical Protective Association (CMPA).

\begin{abstract}
Methods: We conducted a retrospective analysis of college complaint cases involving resident doctors closed by the CMPA, a mutual medicolegal defence organization for more than 100000 physicians, representing an estimated 95\% of Canadian physicians. Eligible cases were those closed between 2008 and 2017 (for time trends) or between 2013 and 2017 (for descriptive analyses). To explore the characteristics of college cases, we extracted the reason for complaint, the case outcome, whether the complaint involved a procedure, and whether the complaint stemmed from a single episode or multiple episodes of care. We also conducted a 10-year trend analysis of cases closed from 2008 to 2017, comparing cases involving resident doctors with cases involving only nonresident physicians.
\end{abstract}

Results: Our analysis included 142 cases that involved 145 patients. Over the 10-year period, college complaints involving residents increased significantly $(p=0.003)$ from 5.4 per 1000 residents in 2008 to 7.9 per 1000 in 2017 . While college complaints increased for both resident and nonresident physicians over the study period, the increase in complaints involving residents was significantly lower than the increase across all nonresident CMPA members $(p<0.001)$. For cases from the descriptive analysis (2013-2017), the top complaint was deficient patient assessment (69/142, 48.6\%). Some patients (22/145, 15.2\%) experienced severe outcomes. Most cases (135/142, 97.9\%) did not result in severe physician sanctions. Our classification of complaints found 106 of $163(65.0 \%)$ involved clinical problems, 95 of $163(58.3 \%)$ relationship problems (e.g., communication) and 67 of 163 (41.1\%) professionalism problems. In college decisions, 36 of $163(22.1 \%)$ had a classification of clinical problem, 66 of $163(40.5 \%)$ a patient-physician relationship problem and 63 of 163 (38.7\%) a professionalism problem. In 63 of 163 (38.7\%) college decisions, the college had no criticism.

Interpretation: Problems with communication and professionalism feature prominently in resident college complaints, and we note the potential for mismatch between patient and health care provider perceptions of care. These results may direct medical education to areas of potential practice improvement.

anadian physician regulatory bodies, hereafter referred to as "colleges," serve the public by regulating the medical profession in accordance with legislation in each province or territory. Practising physicians and postgraduate trainees (residents and fellows) must hold a practice or educational licence from the college in the province or territory in which they practise or study. As part of their mandate to protect patients and the public interest, most colleges must investigate complaints concerning physicians. Our working definition of a complaint was any incident where a regulatory college agreed to investigate a resident.

The Canadian Medical Protective Association (CMPA) is a not-for-profit mutual defence association that assists physician members with medicolegal matters and aims to reduce medicolegal risk through improvements in the safety of care. If a physician member advises the CMPA of a college complaint, the CMPA may assist the member in responding to the matter. Although CMPA data indicate that college complaints

Competing interests: At the time of this study, Allan McDougall and Lisa Calder were employees of the Canadian Medical Protective Association, a not-for-profit mutual defence organization for physicians. No other competing interests were declared.

This article has been peer reviewed.

Correspondence to: Lisa Calder, research@cmpa.org

CMAJ Open 2022 January 18. DOI:10.9778/cmajo.20210026 
reported by all physician members have increased across Canada over the past 10 years, ${ }^{1-3}$ the trend for resident members is unknown. Previous studies have examined disciplinary findings against specific Canadian medical specialties, but these studies did not include residents. ${ }^{3-9}$ Although these studies represent a step toward learning more about college complaints, disciplinary findings are only one possible physician outcome of a college complaint and represent a small fraction of complaint outcomes overall (CMPA: unpublished data, 2020).

It is critical to gain a better understanding of college complaints against residents for several reasons. Exploring the nature of patient complaints provides insight into problems in health care ${ }^{10}$ and may improve patient safety. ${ }^{10-13}$ There is also evidence to suggest patient complaints may be associated with defensive medicine, which is not necessarily beneficial to patient care. ${ }^{14-16}$ Ultimately, a better understanding of the nature of college complaints against resident physicians could benefit the medical education community by identifying areas for practice improvement and helping target educational initiatives to improve patient safety and professionalism, and, in doing so, could mitigate medicolegal risk.

The purpose of this study was to develop a better understanding of the trends and nature of college complaints filed against resident physicians. Our first objective was to examine how the rates of college complaints involving residents have changed over 10 years relative to rates for other physician members of the CMPA. Our second objective was to describe and analyze a more recent sample of college complaints against residents, including resident and patient demographic data, case characteristics and classification categories across college complaints.

\section{Methods}

\section{Design and setting}

In this study, we conducted a retrospective analysis of college complaints involving resident doctors. We use the term "college complaint" to mean complaints against residents relating to patient care and those relating to college investigations prompted from another source. This is a study of closed cases, meaning that a final outcome by a provincial regulator had been determined.

At the time of this study, the CMPA had more than 100000 members, including 12996 residents. About 95\% of Canadian physicians were members, who were thus eligible to seek medicolegal advice and education from the association. Most postgraduate residents in Canada are members of the CMPA, with the exception of most residents practising in the province of Quebec.

\section{Population}

Over a 10-year period of closed cases from 2008 to 2017, we identified 2 groups of college complaints: all college complaints and all complaints with no resident physicians. For inclusion in the trend analysis, college complaints must have been closed between Jan. 1, 2008, and Dec. 31, 2017. We chose periods longer than the 5-year study period we used for the descriptive part of our study to show trends, because medicolegal trends typically change more slowly than health care trends.
We also conducted an analysis of the most recently available 5 years (from Jan. 1, 2013, to Dec. 31, 2017) of college complaints involving residents to describe patient and physician demographic characteristics, case characteristics and complaints classification.

For our analysis of patient and physician demographic data, case characteristics and complaint classifications across college complaints, we excluded all cases for which a college decision was not available. We also excluded cases for which the resident did not appear to be directly involved in a complainant's care or was practising independently during the index occurrence, called "moonlighting" in some regions. Notably, a portion of the cases may not have involved a specific patient (i.e., may have involved a professionalism issue that did not involve patient care).

\section{Data sources}

The CMPA maintains a repository of medicolegal data, routinely collected and coded when members involve the association. College complaints involving patient care are routinely coded by CMPA analysts using international, national and in-house coding frameworks. ${ }^{17}$ Our analysis of resident and patient demographic characteristics and case characteristics used these coded data. For our analysis of complaint categories, we broadened the search criteria to include all complaints involving patient care and complaints from other sources, such as educational supervisors, administrative personnel or other health care providers.

Eligible CMPA data were organized by case, each of which represents an instance during which a physician or multiple physicians contacted the CMPA after being named in a college complaint. To capture and characterize key details about these cases, medical analysts, who are experienced registered nurses, reviewed closed cases and coded specific clinical details using the Canadian enhancement to the International Statistical Classification of Diseases and Related Health Problems ${ }^{18}$ and the Canadian Classification of Health Interventions. ${ }^{19}$ They also coded the level of patient harm using an in-house classification system, a version of the American Society for Healthcare Risk Management (ASHRM) Healthcare Associated Preventable Harm Classification $^{20}$ modified with categories for clinical nuance (Appendix 1, Section 1, available at www.cmajopen.ca/content/10/1/E35/ suppl/DC1). To reduce misclassification, analysts conducted quality assurance reviews of coding on a weekly basis.

\section{Variables}

To characterize resident and patient demographic data, we extracted resident postgraduate year, specialty and age based on year of birth; the province of complaint; and descriptive variables from the patient, including age and self-reported sex. Physician specialty was mapped against the categories included in the Canadian Institute for Health Information National Physician Database (Appendix 1, Section 2). ${ }^{21}$ To explore the characteristics of college cases, we extracted the reason for complaint, case outcome, whether the complaint was appealed, whether the complaint involved a procedure, and whether the complaint stemmed from a single episode of care or multiple episodes of care. 


\section{Classification of complaints}

Our exploration of complaint classifications leveraged several existing frameworks. This involved an in-depth analysis of the full medicolegal file of closed cases from 2013 to 2017 by the primary author (C.C.), who is both a physician and a lawyer. For each complaint, we classified categories underlying the complaint, the college's decision and contributing factors. We also explored level of patient harm according to the ASHRM 7-point scale (Appendix 1). ${ }^{20} \mathrm{We}$ considered patient harm as an outcome that negatively affects a patient's health or quality of life. We used the Health Communication Assessment Tool (HCAT), a validated tool for classifying health care complaints to inform complaint classification. ${ }^{22-24}$ This tool classifies health care complaints using a framework of 26 complaint types, such as medication errors, professional conduct and communication breakdowns. ${ }^{22}$

When the underlying classification of a college complaint or decision was not adequately captured by HCAT, we categorized those complaints and decisions into separate predefined categories agreed on by the research team (see Appendix 1, Section 3 for classification definitions). Over 24 months, quarterly data analysis meetings took place between the coder and A.M. The development of classification definitions was discussed during team coding meetings, and disagreements were resolved through discussion until consensus. We do not report numbers less than 10, as doing so could represent a risk to physician or patient confidentiality, and we have consequently aggregated these data. Scores from HCAT and ASHRM were not used to inform the classification.

\section{Statistical analysis}

To compare complaint rates between physician groups and determine how complaint rates have changed over time, we stratified all CMPA member physicians into 2 groups: residents and all nonresident CMPA physicians. Case rates are the number of cases per physician-year of CMPA membership in the same physician group, multiplied by 1000 . We conducted a 10-year trend analysis of cases closed from 2008 to 2017, comparing cases involving resident doctors with cases involving only nonresident physicians. We calculated each group's relative complaint rates per 1000 physician members of that type per year. We then fitted a linear regression in which the independent variables were physician group and year, and the response variable was complaint rate. We applied an analysis of variance (ANOVA) type III sum of squares test to determine the significance of the change over time and the difference between the 2 physician groups. We generated a trend line using regression estimates for each physician group and calculated the annualized growth rate based on the fitted trend. Statistical tests were 2 -tailed, and we considered $p$ values $<0.05$ to be significant.

We used frequencies and proportions (for categorical variables) and medians and ranges (for continuous variables) to characterize and describe resident and patient demographic data, case characteristics and classification categories across college complaints for cases closed from 2013 to 2017 that involved at least 1 resident. We completed all statistical analyses using SAS 9.4.

\section{Ethics approval}

The Canadian ethics review panel of the Advarra (formerly Chesapeake) Institutional Review Board (Aurora, Ontario) reviewed and approved the study in compliance with Canada's Tri-Council Policy Statement: Ethical Conduct for Research Involving Humans - TCPS 2.

\section{Results}

The CMPA closed 33780 medicolegal cases from January 2013 until December 2017. Of those, 20109 were regulatory complaints, and 469 of those involved a resident (Figure 1). Our resident and patient demographic analysis included 142 cases that involved 145 patients (Table 1). A

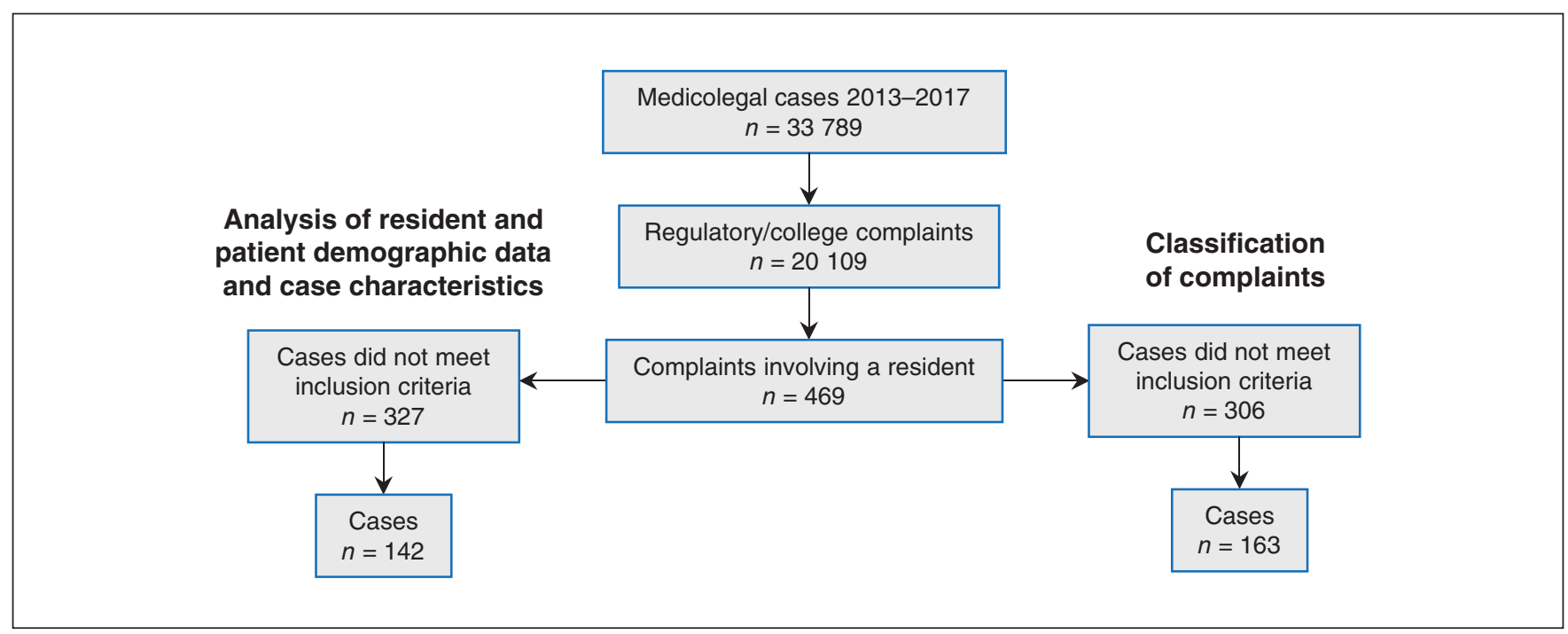

Figure 1: Flow chart of Canadian Medical Protective Association medicolegal cases involving residents from 2013 to 2017. 


\begin{tabular}{|c|c|}
\hline Characteristic & No. $(\%)$ \\
\hline \multicolumn{2}{|l|}{ Residents, ${ }^{*} n=142$} \\
\hline \multicolumn{2}{|c|}{ Resident postgraduate year at time of complaint } \\
\hline 1 & $25(17.6)$ \\
\hline 2 & $36(25.4)$ \\
\hline 3 & $22(15.5)$ \\
\hline 4 & $18(12.7)$ \\
\hline 5 & $9(6.3)$ \\
\hline 6 & 0 \\
\hline Fellow & $27(19.0)$ \\
\hline Unknown & $14(9.9)$ \\
\hline \multicolumn{2}{|l|}{ Resident specialty† } \\
\hline Family medicine & $22(15.5)$ \\
\hline Surgical & $54(38.0)$ \\
\hline Medical & $64(45.1)$ \\
\hline Unknown & $11(7.7)$ \\
\hline \multicolumn{2}{|c|}{ Location of complaint (sorted by CMPA fee region) } \\
\hline Ontario & $101(71.1)$ \\
\hline Alberta and British Columbia & $25(17.6)$ \\
\hline $\begin{array}{l}\text { Saskatchewan, Manitoba, } \\
\text { Newfoundland and Labrador, } \\
\text { Nova Scotia, Prince Edward Island, } \\
\text { New Brunswick, Yukon, Northwest } \\
\text { Territories and Nunavut }\end{array}$ & $22(15.5)$ \\
\hline Quebec & $3(2.1)$ \\
\hline \multicolumn{2}{|l|}{ Resident age range, yr } \\
\hline 24-29 & $57(40.1)$ \\
\hline $30-34$ & $57(40.1)$ \\
\hline $35-39$ & $24(16.9)$ \\
\hline $40-59$ & $13(9.2)$ \\
\hline \multicolumn{2}{|l|}{ Patients, $n=145 \ddagger$} \\
\hline \multicolumn{2}{|l|}{ Patient age range, yr } \\
\hline $0-18$ & $12(8.3)$ \\
\hline $19-29$ & 15 (10.3) \\
\hline $30-49$ & $45(31.0)$ \\
\hline $50-64$ & 27 (18.6) \\
\hline $65-79$ & $22(15.2)$ \\
\hline$\geq 80$ & $8(5.5)$ \\
\hline Unknown & $16(11.0)$ \\
\hline \multicolumn{2}{|l|}{ Patient sex } \\
\hline Female & $86(59.3)$ \\
\hline Male & $58(40.0)$ \\
\hline Unknown & $1(0.7)$ \\
\hline \multicolumn{2}{|c|}{$\begin{array}{l}\text { Note: CMPA = Canadian Medical Protective Association. } \\
{ }^{*} \text { There may be more than } 1 \text { resident named in a complaint. } \\
\text { †See Appendix } 1 \text {, Section } 2 \text { (available at www.cmajopen.ca/content/10/1/E35/ } \\
\text { suppl/DC1) for definitions. } \\
\text { †Some cases involved more than } 1 \text { patient. }\end{array}$} \\
\hline
\end{tabular}

total of 66 cases $(46.5 \%)$ occurred among patients admitted to hospital; 42 (29.6\%) occurred in the emergency department, day surgery or a clinic affiliated with a hospital; and 37 (26.1\%) occurred in an ambulatory care area outside the hospital (there was more than 1 care setting per complaint in some cases). Ontario represented 101 of 142 complaints $(71.1 \%)$.

\section{Trend analysis}

The 10-year trend analysis identified 36490 college complaint cases between 2008 and 2017 (Figure 2). Over the 10 -year study period, the number of college complaints involving residents increased significantly $(p=0.003)$ from 5.4 per 1000 residents in 2008 to 7.9 per 1000 in 2017 (average annualized increase $=5.0 \%, p<0.001$ ). This finding paralleled, although the increase in college complaints involving residents was significantly lower than $(p<0.001)$, the increase in college complaints across all nonresident CMPA members during the same period (average annualized increase $=6.3 \%, p<0.001$ ).

The average case duration for college complaints involving residents $($ mean $=18.5$ mo, median $=14 \mathrm{mo})$ was slightly higher than the average duration for all nonresident CMPA members $($ mean $=17.3 \mathrm{mo}$, median $=13 \mathrm{mo})$. There were no increasing or decreasing trends identified for case duration from 2008 to 2017.

\section{Case characteristics}

In the resident and patient demographic analysis, we assessed 142 cases that involved 145 patients. The top reasons for complaint involved deficient patient assessment, diagnostic error and professionalism (Table 2). Of the 142 cases, 62 (43.7\%) had no peer expert or college criticism and therefore no contributing factors assigned.

For the 80 cases $(56.3 \%)$ with contributing factors, we categorized the contributing factors as provider, team or system factors. Among all cases, 31 (28.9\%) featured more than 1 contributing factor per case. Most cases $(n=53,66.3 \%)$ involved provider factors (Table 3 ). Cases involving team factors $(n=35,43.8 \%)$ included documentation issues $(20 / 35,57.1 \%)$, communication breakdown with the patient $(17 / 35,48.6 \%)$ and communication breakdown between physicians $(5 / 35,14.3 \%)$. System factors were involved in 14 cases $(17.5 \%)$. These included health information technology issues (2/14, 14.3\%); office issues (4/14, 28.6\%); protocol, policy and procedure issues (4/14, 28.6\%); and resource issues $(4 / 14,28.6 \%)$.

With regard to health care-related harm, 27 of 142 cases $(19.0 \%)$ in the resident and patient demographic analysis involved errors in the diagnostic process leading to a misdiagnosis, a missed diagnosis or a delay in diagnosis. The most common types of diagnostic error involved infectious processes and disorders (e.g., pneumonia, otitis media, appendicitis, abscesses), postprocedural complications (e.g., hemorrhage) and missed severity of injuries (e.g., fractured spine, foot). Fourteen cases (9.9\%) involved injuries, and the most common injury involved laceration 


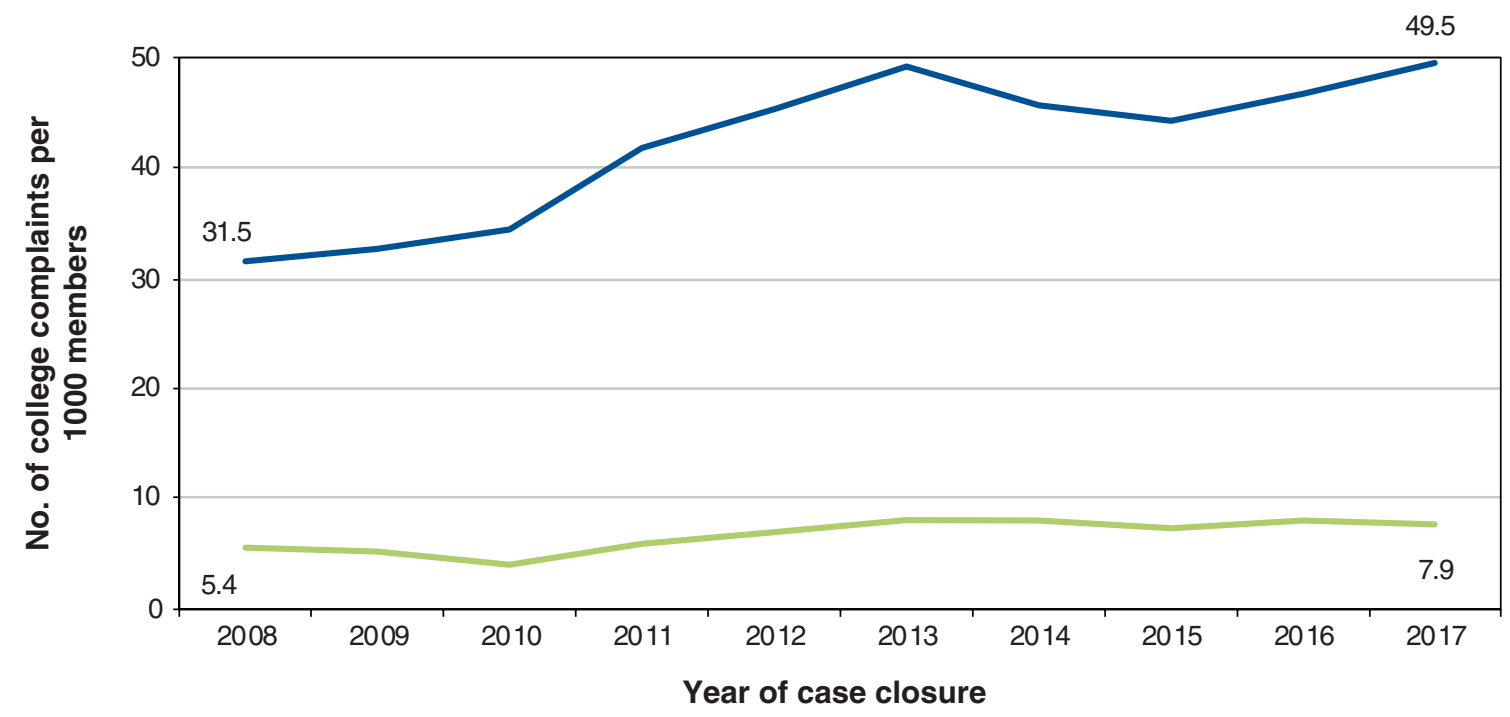

All CMPA members (36 490 cases) $\quad$ Residents (756 cases)

Figure 2: Ten-year trend in number of college complaint cases per 1000 members, by residents versus all nonresident members of the Canadian Medical Protective Association (CMPA).

Table 2: Top 10 reasons for complaints among Canadian
Medical Protective Association college complaint cases
involving residents and patient care, 2013-2017 $(n=142)$

\begin{tabular}{|lc|}
\hline Reason for complaint & No. (\%) \\
\hline 1. Deficient assessment & $69(48.6)$ \\
\hline 2. Diagnostic error & $62(43.7)$ \\
\hline 3. Unprofessional manner & $41(28.9)$ \\
\hline 4. Communication breakdown, patient & $32(22.5)$ \\
\hline 5. Failure to perform test or intervention & $21(14.8)$ \\
\hline 6. Inadequate supervision & $16(11.3)$ \\
\hline 7. Inadequate consent process & $16(11.3)$ \\
\hline 8. Injury associated with health care delivery & $14(9.9)$ \\
\hline 9. Inadequate patient monitoring or follow-up & $13(9.2)$ \\
\hline 10. Sexual impropriety & $13(9.2)$ \\
\hline
\end{tabular}

of blood vessels during an invasive procedure (e.g., central line insertion or thoracentesis) or during surgery. Among the 145 patients who were included in the 142 cases, 22 (15.2\%) experienced severe outcomes, including death in 13 cases $(9.0 \%)$.

Most complaints $(135 / 142,95.1 \%)$ did not result in severe sanctions for the resident involved. Seventy-nine of 142 cases $(55.6 \%)$ were dismissed for the resident with no further action taken, and in 56 cases (39.4\%), residents were given an educational or remedial disposition. In 7 cases, residents received more severe sanctions (4.9\%).

\section{Complaint classifications}

Our classification of complaints focused on a sample of 163 of $469(34.7 \%)$ complaints involving a resident. Ontario represented 115 of 163 complaints (70.6\%). Most complaints were filed by patients $(57 / 163,35.0 \%)$ and their advocates $(53 / 163,32.5 \%)$. About one-third of cases $(53 / 163,32.5 \%)$ were filed by personnel other than patients or their advocates. These included complaints filed by academic personnel $(23 / 163,14.1 \%)$, administration $(12 / 163,7.4 \%)$, other health care professionals $(9 / 163,5.5 \%)$ and other members of the public $(7 / 163,4.3 \%)$. One case was self-reported, and 1 was unknown.

Cases included in the classification of complaints similarly did not lead to severe resident sanctions: 84 complaints $(51.5 \%)$ were dismissed with no further action taken, and in 60 complaints (36.8\%), residents were given an educational or remedial disposition. Conversely, 19 complaints (11.7\%) resulted in severe sanctions, which included voluntary resignation, suspension, limitations placed on practice, citation or written caution, erased or revoked licence, and remedial agreement. Several of the cases involving a suspension also included limitations on practice once the resident returned to practice (e.g., cannot prescribe opioids, must take part in physician health program, must have chaperone present). A total of 25 of 163 cases (15.3\%) were appealed by the resident.

Out of the 110 cases that involved complaints filed by patients or their advocates, 10 (9.1\%) involved a complaint arising from an incident in which a patient had more than 1 interaction (on separate dates) with the resident, and 29 of these cases (26.4\%) involved procedures. 


\begin{tabular}{|c|c|c|}
\hline Factor & $\begin{array}{l}\text { No. }(\%) \text { of } \\
\text { complaints }\end{array}$ & Example \\
\hline Clinical decision-making & $27(50.9)$ & \\
\hline Thoroughness of assessment & $19(35.8)$ & $\begin{array}{l}\text { Failure to obtain detailed history and conduct focused physical } \\
\text { examination }\end{array}$ \\
\hline Diagnosis & $13(24.5)$ & $\begin{array}{l}\text { Failure to reassess in timely manner when condition } \\
\text { deteriorates or after giving medications }\end{array}$ \\
\hline Management errors & $7(13.2)$ & $\begin{array}{l}\text { Inappropriate disposition or delay or failure to consult with } \\
\text { senior residents or staff }\end{array}$ \\
\hline Lack of situational awareness & $15(28.3)$ & \\
\hline Failure to read patient record & $6(11.3)$ & $\begin{array}{l}\text { Reading patient's previous record would likely have prompted } \\
\text { ordering a diagnostic test or led to a different differential diagnosis }\end{array}$ \\
\hline $\begin{array}{l}\text { Lack of self-awareness in resident's knowledge, } \\
\text { skill, technique, training, education }\end{array}$ & $6(11.3)$ & $\begin{array}{l}\text { Resident showed poor judgment in not seeking supervisor's } \\
\text { assistance before performing invasive procedure }\end{array}$ \\
\hline Health, conduct and boundary issues* & $20(37.7)$ & Use of cellphone during patient examination \\
\hline Procedural violations & $17(32.1)$ & $\begin{array}{l}\text { Failure to complete checklist before invasive procedure; failure } \\
\text { to provide adequate supervision of residents }\end{array}$ \\
\hline
\end{tabular}

The most frequent classification in college complaints was clinical problems (106/163, 65.0\%), whereas the top classification in college decisions was relationship problems (66/163, $40.5 \%)$. More than one-third of cases (63/163 cases, $38.7 \%)$ had no college criticism and were coded as groundless. Table 4 provides complete information on how many times a classification was found in college complaint allegations and college decisions.

When examining college decisions by outcome, the top 3 classifications in college decisions in cases that were dismissed with no further action taken were as follows: groundless (60/84, 71.4\%), professionalism problems (12/84, $14.3 \%$, with 7 being documentation issues) and relationship (e.g., communication or respect) problems (11/84, 13.1\%).

Of the 60 of 163 cases (36.8\%) in which residents were provided with an educational or remedial disposition, the top 3 classifications in college decisions were relationship problems (39/60, 65.0\%), professionalism problems $(32 / 60,53.3 \%)$ and clinical problems with quality or safety $(29 / 60,48.3 \%)$.

Of the 19 of 163 college decisions (11.7\%) in which there was concern expressed by the college and sanctions imposed, the top 3 classifications in college decisions were professionalism problems (19/19, 100.0\%); relationship problems $(17 / 19,89.5 \%)$; and criminal, ethical or boundary issues (e.g., fraud, prescription diversion and driving while impaired) $(13 / 19,68.4 \%)$.

\section{Interpretation}

Our results indicate that rates of complaints involving residents have increased over time, but remain low. Problems with communication and professionalism feature prominently in these complaints, and we note the potential for mismatch between patient and health care provider perceptions of care.
This study contributes to a growing body of literature showing how complaints data provide important information to improve patient safety. ${ }^{10-14}$ As the medicolegal curriculum has traditionally not been a focus of residency programs, our results underscore the need to address college complaints in medical education and provide guidance to programs for potentially improving the quality of clinical practice and mitigating medicolegal risk.

Despite complainants' common perceptions of poor clinical care, college decisions reflected a classification of clinical problems in only 36 of 163 cases (22.1\%). Our classification of complaints indicated a substantial proportion of college complaint decisions $(63 / 163,38.7 \%)$ were coded as groundless. This illustrates that although patients and other complainants may feel there has been a particular wrong committed, this is not necessarily affirmed after investigation of the complaint, highlighting the mismatch between patient and health care provider perceptions of care.

Some research has reported surprisingly high levels of unprofessional, fraudulent and deceitful behaviours among resident physicians in the United States. ${ }^{25}$ When examining complaints that had educational or remedial dispositions, we found that patient-physician relationship and professionalism problems were more prevalent than clinical problems in college decisions. We also found that documentation was often criticized by colleges, even when poor documentation was not a central issue in the original complaint. Professionalism and documentation represent potential educational areas that could be addressed by targeted interventions to increase awareness for what can prompt college complaints against residents and negatively affect college decision outcomes. ${ }^{26,27}$ 


\begin{tabular}{|c|c|c|}
\hline Classification & No. $(\%)$ in complaint* & No. $(\%)$ in decision \\
\hline \multicolumn{3}{|l|}{ HCAT category } \\
\hline Clinical problem & $106(65.0)$ & $36(22.1)$ \\
\hline Quality & $96(58.9)$ & $32(19.6)$ \\
\hline Safety & $44(27.0)$ & $24(14.7)$ \\
\hline Relationship problem & $95(58.3)$ & $66(40.5)$ \\
\hline Communication & $63(38.7)$ & $47(28.8)$ \\
\hline Listening & $11(6.7)$ & $8(4.9)$ \\
\hline Respect and patient rights & $58(35.6)$ & $40(24.5)$ \\
\hline Management problem & $5(3.1)$ & $5(3.1)$ \\
\hline Environment & $1(0.6)$ & $3(1.8)$ \\
\hline Institutional processes & $5(3.1)$ & $3(1.8)$ \\
\hline \multicolumn{3}{|l|}{ Supplementary category } \\
\hline Professionalism & $67(41.1)$ & $63(38.7)$ \\
\hline Physician conduct & $58(35.6)$ & $42(25.8)$ \\
\hline Deceit or dishonesty & $22(13.5)$ & $21(12.9)$ \\
\hline Documentation & $10(6.1)$ & $23(14.1)$ \\
\hline Criminal, ethical and boundary violations & $33(20.2)$ & $23(14.1)$ \\
\hline Fraud & $9(5.5)$ & $9(5.5)$ \\
\hline Boundary crossing or violation & $18(11.0)$ & $11(6.7)$ \\
\hline Other charge or investigation & $13(8.0)$ & $8(4.9)$ \\
\hline Inappropriate prescribing & $6(3.7)$ & $6(3.7)$ \\
\hline Academic & $6(3.7)$ & $15(9.2)$ \\
\hline Failure to ask for help & $1(0.6)$ & $5(3.1)$ \\
\hline Inadequate supervision & $6(3.7)$ & $10(6.1)$ \\
\hline Groundless & NA & $63(38.7)$ \\
\hline \multicolumn{3}{|c|}{$\begin{array}{l}\text { Note: HCAT = Health Communication Assessment Tool, NA = not applicable. } \\
{ }^{*} \text { There is often more than } 1 \text { subcategory of classification in a case (i.e., subcategories will often add up to greater than the total of } \\
\text { the category because a resident was found to have a problem with both listening and communication, for example). See } \\
\text { Appendix } 1 \text {, Section } 3 \text { (available at www.cmajopen.ca/content/10/1/E35/suppl/DC1) for classification definitions. }\end{array}$} \\
\hline
\end{tabular}

One US study found that low professionalism ratings on annual evaluations predicted an increased risk for disciplinary actions from state licensing boards. ${ }^{26}$ This adds further support to the suggestion that professionalism should be appropriately taught and evaluated in residency education. We believe strategies at the postgraduate medical education level can help improve resident professional behaviour and the physician-patient relationship, thereby potentially decreasing the chances of residents receiving a complaint. Postgraduate educators should also consider that such educational strategies can help support residents to cope with and manage complaints when they occur.

Our study also found that a perception of problems with clinical care is the most common reason patients complain to colleges about residents. Evidence exists that physicians who reported overall participation in continuing professional development activities were significantly less likely to receive quality of care-related complaints than those who did not report par- ticipating in such activities. ${ }^{27} \mathrm{We}$ therefore hypothesize that allocation of more resources during residency to medicolegal education by postgraduate medical education leaders could lessen the chance of their residents receiving a complaint.

\section{Limitations}

Several limitations to our study should be considered. Some residents, particularly a large proportion from Quebec, are not CMPA members. Moreover, an unknown proportion of others who are CMPA members may have received college complaints but not voluntarily reported these cases to the CMPA. The demographic data we report were not collected for research purposes; therefore, we were unable to report on specific specialty and other practice characteristics owing to confidentiality concerns. Although comparing complaints across residents' specialties is a topic warranting further study, our data were not sufficient to compare results across specialties. Further to our methods, although we used valid tools 
(e.g., HCAT $)^{22-24}$ to inform our work, none of the data analysis tools used in our study were validated.

According to the Canadian Post-M.D. Education Registry, residents from the province of Quebec made up 23.8\% of Canadian residency spots between 2008 and 2017.28 The lack of information regarding the medicolegal experience of most of these residents undermines the representativeness of our results as a national sample. Additionally, while Ontario has the largest population of CMPA resident members, we observed that it also had a disproportionately high number of complaints. There can be numerous reasons why these variations exist, including different decision-making processes among colleges. Therefore, caution should be taken when extrapolating the summary results to local jurisdictions. Another limitation involves the use of only 1 analyst involved in the coding of complaint classifications. We acknowledge that our college case analysis may also have been negatively influenced by outcome and hindsight biases. ${ }^{29-32}$

\section{Conclusion}

Our study highlights that rates of complaints against residents have increased over time, but at a slower rate than those against nontrainee physicians. Problems with communication skills and professionalism feature prominently among college complaints experienced by residents training in Canada. Classification of complaints also showed the potential for mismatch between patient and health care provider perceptions of care. The improved understanding of college complaints against residents our study provides has the potential to benefit patients, residents, educators and colleges.

\section{References}

1. 2016 Annual Report. Ottawa: Canadian Medical Protective Association; 2017

2. 2019 Annual Report. Ottawa: Canadian Medical Protective Association; 2020.

3. Moulton D. College complaints to CMPA increase. CMA7 2016;188:791.

4. Alam A, Khan J, Liu J, et al. Characteristics and rates of disciplinary findings amongst anesthesiologists by professional colleges in Canada. Can 7 Anaesth 2013;60:1013-9.

5. Alam A, Klemensberg J, Griesman J, et al. The characteristics of physicians disciplined by professional colleges in Canada. Open Med 2011;5:e166-72.

6. Alam A, Kurdyak P, Klemensberg J, et al. The characteristics of psychiatrists disciplined by professional colleges in Canada. PLoS One 2012;7:e50558.

7. Alam A, Matelski JJ, Goldberg HR, et al. The characteristics of international medical graduates who have been disciplined by professional regulatory colleges in Canada: a retrospective cohort study. Acad Med 2017;92:244-9.

8. Liu JJ, Alam AQ, Goldberg HR, et al. Characteristics of internal medicine physicians disciplined by professional colleges in Canada. Medicine (Baltimore) 2015;94:e937.

9. Jeyalingam T, Matelski JJ, Alam AQ, et al. The characteristics of physicians who are re-disciplined by medical boards: a retrospective cohort study. $7 t$ Comm 7 Qual Patient Saf 2018;44:361-5.

10. Donaldson L. An organization with a memory: report of an expert group on learning from adverse events in the NHS chaired by the Chief Medical Officer. London (UK): The Stationary Office; 2000.

11. Gillespie A, Reader TW. Patient-centered insights: using health care complaints to reveal hot spots and blind spots in quality and safety. Milbank Q 2018;96:530-67.

12. Weingart SN, Pagovich O, Sands DZ, et al. What can hospitalized patients tell us about adverse events? Learning from patient-reported incidents. 7 Gen Intern Med 2005;20:830-6.

13. de Feijter JM, de Grave WS, Muijtjens AM, et al. A comprehensive overview of medical error in hospitals using incident-reporting systems, patient complaints and chart review of inpatient deaths. PLoS One 2012;7:e31125.

14. Pichert JW, Hickson G, Moore I. Using patient complaints to promote patient safety. In: Henriksen K, Battles JB, Keyes MA, et al., editors. Advances in patient safety: new directions and alternative approaches (Vol. 2: Culture and redesign). Rockville (MD): Agency for Healthcare Research and Quality (US); 2008.

15. Bourne T, Vanderhaegen J, Vranken R, et al. Doctors' experiences and their perception of the most stressful aspects of complaints processes in the UK: an analysis of qualitative survey data. BMF Open 2016;6:e11711.
16. Wada K, Yoshikawa T, Goto T, et al. Association of depression and suicidal ideation with unreasonable patient demands and complaints among Japanese physicians: a national cross-sectional survey. Int 7 Behav Med 2011;18:384-90.

17. McCleery A, Devenny K, Ogilby C, et al. Using medicolegal data to support safe medical care: a contributing factor coding framework. 7 Healthc Risk Manag 2019;38:11-8.

18. ICD-10: International Statistical Classification of Diseases and Related Health Problems, 10th Revision. Geneva: World Health Organization; 2011.

19. Canadian Classification of Health Interventions. Ottawa: Canadian Institute for Health Information. Available: https://www.cihi.ca/en/codes-and-classifications (accessed 2019 Sept. 3).

20. Hoppes M, Mitchell JL, Venditti EG, et al. Serious safety events: getting to zero. 7 Healthc Risk Manag 2013;32:27-45.

21. National physician database data release, 2018-2019: methodology notes. Ottawa: Canadian Institute for Health Information; 2020. Available: https://www.cihi.ca/ sites/default/files/document/national-physician-database-data-release-2018-2019 -methodology-notes-en.pdf (accessed 2020 Sept. 6).

22. Reader TW, Gillespie A, Roberts J. Patient complaints in healthcare systems: a systematic review and coding taxonomy. BM7 Qual Saf 2014;23:678-89.

23. Gillespie A, Reader TW. The Healthcare Complaints Analysis Tool: development and reliability testing of a method for service monitoring and organisational learning. BM7 Qual Saf 2016;25:937-46.

24. Bogh SB, Kerring JH, Jakobsen KP, et al. Healthcare Complaints Analysis Tool: reliability testing on a sample of Danish patient compensation claims. BM7 Open 2019;9:e33638.

25. Fargen KM, Drolet BC, Philibert I. Unprofessional behaviors among tomorrow's physicians: review of the literature with a focus on risk factors, temporal trends, and future directions. Acad Med 2016;91:858-64.

26. Papadakis MA, Arnold GK, Blank LL, et al. Performance during internal medicine residency training and subsequent disciplinary action by state licensing boards. Ann Intern Med 2008;148:869-76.

27. Wenghofer EF, Campbell C, Marlow B, et al. The effect of continuing professional development on public complaints: a case-control study. Med Educ 2015;49:264-75.

28. Association of Faculties of Medicine of Canada. Ottawa: Canadian Post-M.D. Education Registry (CAPER). Available: https://caper.ca (accessed 2020 Sept. 6).

29. Hugh TB, Tracy GD. Hindsight bias in medicolegal expert reports. Med 7 Aust 2002;176:277-8.

30. Annunziata A. Retrospective bias in expert evidence: effects on patient and doctor safety. Emerg Med Australas 2009;21:80-3.

31. Henriksen K, Kaplan H. Hindsight bias, outcome knowledge and adaptive learning. Qual Saf Health Care 2003;12(Suppl 2):ii46-50.

32. Hugh TB, Dekker SWA. Hindsight bias and outcome bias in the social construction of medical negligence: a review. 7 Law Med 2009;16:846-57.

Affiliations: Department of Emergency Medicine (Crosbie, Abu-Laban), University of British Columbia, Vancouver, BC; Canadian Medical Protective Association (McDougall, Calder); Faculty of Education (McDougall), University of Ottawa, Ottawa, Ont.; Division of Plastic Surgery (Pangli), Faculty of Medicine, University of British Columbia, Vancouver, BC; Clinical Epidemiology Program (Calder), Ottawa Hospital Research Institute, Ottawa, Ont.

Contributors: Charlotte Crosbie, Lisa Calder, Allan McDougall and Riyad Abu-Laban designed the study. Charlotte Crosbie and Allan McDougall collected the data. Charlotte Crosbie and Harpreet Pangli performed the data analysis. Charlotte Crosbie drafted and revised the manuscript, with extensive review by Lisa Calder, Allan McDougall, Riyad AbuLaban and Harpreet Pangli. All authors gave final approval of the version to be published and agreed to be accountable for all aspects of the work.

Funding: This study was internally funded by the Canadian Medical Protective Association.

Content licence: This is an Open Access article distributed in accordance with the terms of the Creative Commons Attribution (CC BY-NC-ND 4.0) licence, which permits use, distribution and reproduction in any medium, provided that the original publication is properly cited, the use is noncommercial (i.e., research or educational use), and no modifications or adaptations are made. See: https://creativecommons.org/licenses/by-nc-nd/4.0/

Data sharing: Data sharing for this study is unavailable.

Acknowledgements: The authors acknowledge the following individuals who contributed to data capture, data cleaning, quality assurance and manuscript submission: Anne Steen, Qian Yang, Cathy Zhang, Syeda Faisal, Ria De Gorter and Robert Hudson from the Canadian Medical Protective Association, and Les Forward of the Canadian Post-M.D. Education Registry.

Supplemental information: For reviewer comments and the original submission of this manuscript, please see www.cmajopen.ca/content /10/1/E35/suppl/DC1. 